\title{
The VACD-Thal Protocol in the Treatment of Multiple Myeloma in Abidjan (Côte D'ivoire)
}

Nanho Danho C1, Packo Dieu-le-veut SS ${ }^{1 *}$, N'dathz Emeraude C1, Boidy $\mathbf{K}^{1}$, Meité N'dogomo $^{1}$, Silué Dohoma $\mathbf{A}^{1}$, Kamara Ismael ${ }^{1}$, Mpibi Mpiana B ${ }^{1}$, Botti Rénée P1, Djeket Ruth¹, Bokoum Saida ${ }^{1}$, Diakité Mamady², Tolo Aissata ${ }^{1}$, Koffi Kouassi G ${ }^{1}$ and Sanogo Ibrahima ${ }^{1}$

\section{Research Article \\ Volume 3 Issue 2}

Received Date: August 23, 2019

Published Date: August 28, 2019

DOI: $10.23880 / \mathrm{hij}-16000144$

1Department of Clinical Hematology, University of Felix Houphouet Boigny, Cote d'Ivoire

${ }^{2}$ Department of Clinical Hematology, University Gamma Abder Nasser of Conakry, Guinea

*Corresponding author: Packo Dieu-le-Veut Saint-Cyr Sylvestre, Department of Clinical Hematology, University of Felix Houphouet Boigny, P.O. Box 1439, Abidjan 04, Cote d’Ivoire, Tel: 0022589542209; Email: stcyrpacko@yahoo.fr

\section{Abstract}

Background: The new drugs currently used in the treatment of myeloma are available in Africa but inaccessible because of their high cost. That's why treatment of multiple myeloma remains a challenge in our sector.

Objective: To evaluate the VACD-Thal protocol in the treatment of myeloma in Côte d'Ivoire.

Materials and Methods: It's was a prospective and descriptive study with duration of two years at the department of clinical hematology in Côte d'Ivoire. We included the patients with multiple myeloma, diagnosed according to the IMWG 2015 criteria, treated and follow with protocol VACD-Thal. The variables analysed were demographic, paraclinical, therapeutic and evolutionary data. Survival curves were plotted using the Kaplan Meier method.

Results: We included 33 patients. There were 22 men (66.7\%) and 11 women (33.3\%). The average age was 60.5 years with extremes of 42 and 79 years. $24.2 \%$ of patients worked in industrial enterprises and $24.24 \%$ were exposed to herbicides and pesticides. HIV and arterial hypertension were the comorbidities. The symptoms were dominated by deteriorisation of general state (63.3\%), bone pain (48.5\%), pathological fractures (18.2\%), anemia (93.9\%) and hypercalcemia (45.4\%). The typical myeloma was predominant (81.8\%). Our patients were classified ISS III in $78.8 \%$ of case. The overall therapeutic response was observed in $84.8 \%$ of cases with a very good partial response in $63.64 \%$ of cases and a partial response in $21.2 \%$ of cases. Overall survival at 6 months was $87 \%$ and $88.5 \%$ at one year of survival. Conclusion: Combination of immunomodulator with conventional chemotherapy such as VACD-Thal protocol has done the better results compared to chemotherapy alone. 
Abbreviations: MM: Multiple Myeloma; CR: Complete Response; PR: Partial Response; VGPR: Very Good Partial Response; SD: Stable Disease; PD: Progressive Disease.

\section{Introduction}

Multiple myeloma (MM) represented about $1 \%$ of all cancers, $10 \%$ of hematological malignancies and $2 \%$ of cancer deaths [1]. In Europe, its incidence is 4.5-6.00 / 100,000 inhabitants / year; while in the United States it is 4.3 per 100,000 inhabitants [2,3]. In Côte d'Ivoire, the hospital incidence was estimated at 2.9 cases / year between [4]. The therapeutic history of this disease is marked by the advent of new molecules such as immunomodulators since 1957, proteasome inhibitors, monoclonal antibodies and histone deacetylase inhibitors. In contrast, the use of conventional chemotherapy is devolved to our countries with low economic income, so that the therapeutic management of myeloma remains a problem in sub-Saharan Africa, particularly in Côte d'Ivoire. Indeed, these new therapeutic molecules are available in Africa in hospitals but inaccessible for the majority of our patients because of the high cost. Only $2 \%$ of the general population is covered by health insurance. Thus conventional chemotherapy remains the only therapeutic alternative for the management of our patients. Some previous studies with chemotherapy alone with the alternate VACD / VBMP protocol, 12 to 16 cycles reported an RP of $47 \%$ [4]. Our study proposes to evaluate the association of the chemotherapyimmunomodulator in the management of MM in Africa.

\section{Materials and Methods}

We conducted a prospective and descriptive study at the clinical hematology department in Abidjan (Côte d'Ivoire). It covered a period of two years (December 2017 to January 2019) and concerned patients with multiple myeloma. We included in the study, the new case of multiple myeloma diagnosed according to the International Myeloma Working Group 2015 criteria; Patients with MM in retreatment. We selected those patients with a low economic level and can't to buy the news molecules for the standard treatment. 33 patients were selected and gave their consent. They received the treatment with VACD-Thal protocol according to the posology and the following modes of administration:
Vincristine $1,4 \mathrm{mg} / \mathrm{m} 2$ in IVL at day 1

Melphalan (Alkeran) $5 \mathrm{mg} / \mathrm{m} 2$ of day1 to day 4, per so Cyclophosphamide $100 \mathrm{mg} / \mathrm{m} 2$ day 1 to day 4, per os Dexamethasone $40 \mathrm{mg}$ day 1 to day 4 per os Thalidomide $100 \mathrm{mg} /$ day, continuously (Day1 = Day 28)

The cycles were sequential, separated of 28 days with a total of 12 cycles. Adjuvant therapy included bisphosphonates, anti-infective (Antibiotics and Antiviral), the management of severe renal, alkaline over hydration if hypercalcemia, analgesics, surgical treatment of pathological fractures and compressions spinal cord.

Clinical surveillance concerned the treatment adherence and the evolution of clinical symptoms. Biological surveillance (blood cell count, ionogram) were performed on Day 7, Day 14, Day 28. The paraclinical evaluation examinations were performed at 6 cycles and at the end of 12 cycles depending on the initial clinical presentation of the patient. These patients were followed for 24 months.

We evaluated the parameters of the therapeutic response according to the criteria of the IMWG which define: the complete response (CR), a very good partial response (VGPR), a partial response (PR), a stable disease (SD) and a progressive disease (PD). CR, VGPR and PR were defined as good therapeutic responses. We defined overall survival over 6 months and one (01) year.

\section{Data Entry and Statistical Analyses}

The data analysis was performed with Epi info Version 3.5.1 software. The results were entered and the tables and figures were designed using the Word, Excel version 2010 software. The calculation of survival was done according to the Kaplan-Meier method.

\section{Results}

We included 33 patients in our study. Table 1 summarizes the distribution of our patients according to epidemiological, clinical, biological and prognostic data. The Tables $2 \& 3$ described respectively the therapeutic responses and the secondary effects of chemotherapy. As for figure 1, it describes the Overall survival curve. 


\begin{tabular}{|c|c|}
\hline Variables & Numbers (\%) \\
\hline \multicolumn{2}{|c|}{$\begin{array}{c}\text { Ages (years) : average and extremes: } \\
60,5[42-79]\end{array}$} \\
\hline$<50$ & $3(9,1)$ \\
\hline $50-60$ & $14(42,4)$ \\
\hline$>60$ & $16(48,5)$ \\
\hline \multicolumn{2}{|l|}{ Sex : } \\
\hline men & $22(66,7)$ \\
\hline Female & $11(33,3)$ \\
\hline \multicolumn{2}{|l|}{ Professional occupation } \\
\hline Housewives & $3(9,1)$ \\
\hline Executives & $2(6,1)$ \\
\hline Trades people & $7(21,2)$ \\
\hline farmers & $12(13,79)$ \\
\hline others & $9(27,3)$ \\
\hline \multicolumn{2}{|l|}{ Performance status } \\
\hline 0 & $0(0,0)$ \\
\hline 1 and 2 & $12(9,1)$ \\
\hline 3 and 4 & $21(63,3)$ \\
\hline \multicolumn{2}{|l|}{ Bone syndrome } \\
\hline Bone pains & $10(30,3)$ \\
\hline Fractures & $6(18,2)$ \\
\hline \multicolumn{2}{|l|}{ Type of myéloma } \\
\hline Typic myéloma typique & $27(81,8 \%)$ \\
\hline free light chains myéloma & $5(15,1)$ \\
\hline nonsecretory myéloma & $1(3,0)$ \\
\hline \multicolumn{2}{|c|}{ Type of monoclonal immunoglobulin } \\
\hline $\operatorname{IgG}$ & $28(84,8)$ \\
\hline $\operatorname{IgA}$ & $4(12,1)$ \\
\hline \multicolumn{2}{|l|}{ Hemoglobin level (g/dl) } \\
\hline$<8$ & $11(33,3)$ \\
\hline 08-10 & $9(27,3)$ \\
\hline$>10$ & $13(39,4)$ \\
\hline \multicolumn{2}{|c|}{ Bone marrow plasmacytosis (\%) } \\
\hline$<10$ & $1(3,0)$ \\
\hline $10-30$ & $22(66,7)$ \\
\hline$>30$ & $10(30,3)$ \\
\hline \multicolumn{2}{|l|}{ Blood calcium (mg/l) } \\
\hline$<120$ & $18(54,6)$ \\
\hline$>120$ & $15(45,4)$ \\
\hline \multicolumn{2}{|l|}{ Serum créatinine (mg/l) } \\
\hline Normal & $14(42,4)$ \\
\hline High & $19(57,6)$ \\
\hline \multicolumn{2}{|l|}{ Radiological signs } \\
\hline No lytic lesions & $6(18,2)$ \\
\hline 1-2 lytic lesions & $10(30,3)$ \\
\hline$>3$ lytic lesions & $11(33,3)$ \\
\hline \multicolumn{2}{|l|}{ Stage of ISS } \\
\hline Stage I & $2(6,1)$ \\
\hline Stage II & $5(15,2)$ \\
\hline Stage III & $26(78,8)$ \\
\hline
\end{tabular}

Table 1: Epidemiological, clinical, biological and pronostic features.

\begin{tabular}{|c|c|}
\hline Variables & Numbers (\%) \\
\hline Thérapeutique responses & \\
\hline VGPR & $21(63,6 \%)$ \\
\hline PR & $7(21,2 \%)$ \\
\hline Stable disease & $1(3,0 \%)$ \\
\hline Progression disease & $4(12,1 \%)$ \\
\hline Outcome & \\
\hline Living and on treatment & $24(72,7 \%)$ \\
\hline Lost to followup & $6(18,2 \%)$ \\
\hline Dead & $3(9,1 \%)$ \\
\hline
\end{tabular}

Table 2: Therapeutic response and outcome feature.

\begin{tabular}{|c|c|}
\hline Variables & Numbers (\%) \\
\hline Non-Hematologic Toxicity \\
\hline Peripheral neuropathies & $21(63,6)$ \\
\hline Digestive disorders & $5(15,1)$ \\
\hline Renal failure & $2(6,1)$ \\
\hline Metabolic disorders & $3(9,1)$ \\
\hline Deep venous thrombosis & $2(6,1)$ \\
\hline \multicolumn{2}{|c|}{ Hematologic Toxicity } \\
\hline Neutropenia & $18(54,5)$ \\
\hline Anemia & $6(18,2)$ \\
\hline bicytopenia & $4(12,1)$ \\
\hline pancytopenia & $5(15,1)$ \\
\hline
\end{tabular}

Table 3: Secondary effects of treatment features.

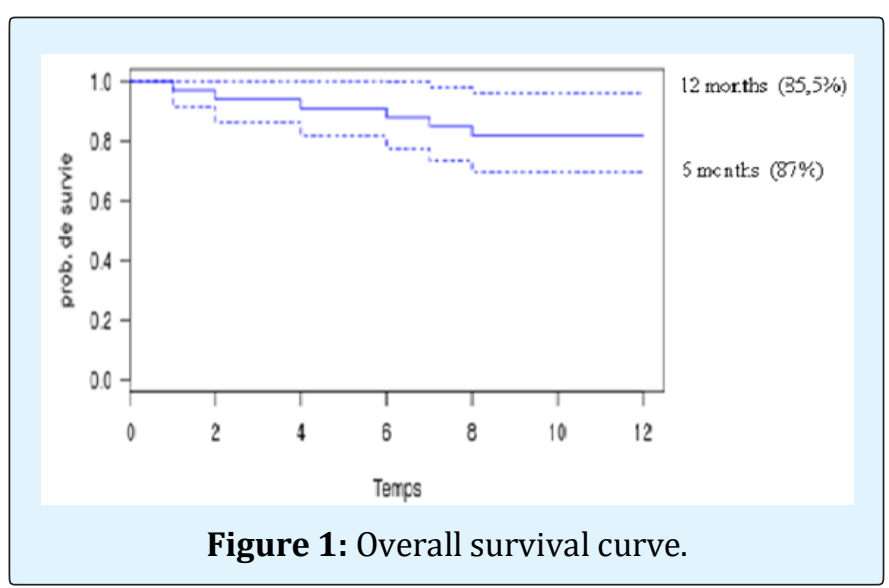

\section{Discussion}

Our study involved 33 patients with multiple myeloma and consisted to evaluate the VACD-Thal therapeutic combination to make it a therapeutic alternative for patients with low financial means. The average age of our patients was 60.5 years with extremes of 42 to 79 years. Patients older than 60 years were the majority with $48.5 \%$ of cases. Our results were similar to African data 
that reported average ages between 56 and 63 years $[5,6]$. The study of Kyle et al in the USA and Bataille, et al. in France reported an average age of 61.5 and 65 , respectively $[7,8]$. This could be explained by the experience of life which is lower in Africa unlike developed countries. For the sexes, we constated a predominance of male sex similar at the data of the literature [4,9]. The predominance of women has been found in Cameroon [10]. The deterioration of the general state and bone pain were mainly observed as symptom in respectively $63.3 \%$ and $48.5 \%$. These symptoms were found in the Nigerian and Central African studies [11-14]. This finding was related to the delay of diagnosis of our patients because of low financial means but also the accessibility to a consultation center so that most of our patients are seen late most often at the stage of complications. These complications were: anemia (60.6\%), hypercalcemia (45.4\%), renal failure (57.6\%), and pathological fracture (18.2\%). Our results were similar to the Cameroonian and Tunisian series $[10,15]$. IgM kappa MM was predominant in our series, identical in European and African studies $[4,8,9,15,16]$. In terms of prognosis, the majority of our patients were classified at stage III of the ISS (78.8\%). A study published in 2017 by Nwabuko, et al. showed the predominance of stage III of the ISS [11]. Our results were different from the European series which reported stage I with a proportion of $32 \%$ [17-19]. This difference is explained by the fact that our patients consulted late sometimes at the stage of complications due to lack of financial means but also the distance to health centers consultations. Stage III of the ISS is attributed to the independent factor of mortality and associated with a pejorative factor $[11,13,20]$.

This would raise the challenge of management of myeloma in Black Africa. Indeed, the prognosis of the disease is a factor impacting the clinico-biological characteristics, the treatment, the therapeutic responses and the survival of the patients in our environment in Africa where the financial resources are limited. The therapeutic evaluation 12-month after the treatment with the VACD-Thal protocol noted a good response in $84.8 \%$ of cases. It was $63.6 \%$ of VGPR, $21.2 \%$ PR. Our results are superior to those of Cameroon and Tunisia, which found respectively a good response in $60 \%$ and $65.2 \%$ of cases with chemotherapy alone and superior to the previous study of Tolo et al in Côte d'Ivoire, which found 7\% of PR with chemotherapy alone $[4,15,21]$. The secondary effects of our protocol were dominated by peripheral neuropathies $(63.6 \%)$, neutropenia $(54.5 \%)$ and anemias (18.2\%). These adverse effects were also reported by Legriel S, et al. [22]. These adverse effects had an impact on the therapeutic compliance of our patients and could influence the therapeutic responses. The prior knowledge of these effects, which have been described in the literature, has allowed us to adapt a therapeutic approach based on close surveillance and the management of its effects during sequential treatments. We deplored $9.1 \%$ of deaths related to the evolution of the myeloma disease. The death rate in previous study in Africa was $37 \%$ in Côte d'Ivoire and $26.7 \%$ in Bangui [4,14]. As for the survival of our patients, the overall probability of survival at 6 months was $87 \%$. It was $88.5 \%$ at 12 months with extremes that ranged from $81 \%$ to $96 \%$. Our data were superior to those of Ngouadjeu Dongho TE et al, who reported an overall follow-up at $26,90 \%$ at 5 years with the VMCP protocol [21]. In the series of Tolo, et al. the probability of survival at 6 months was 51\%, results inferior to our [4].

\section{Conclusion}

The combination of an immunomodulator with conventional chemotherapy by the VACD + THAL protocol has resulted in better results compared to this chemotherapy alone. Like the new MM molecules whose cost is beyond the purses for a large part of the African population, the VACD-Thal protocol could be a therapeutic alternative in our poor countries.

\section{Acknowledgments}

The authors welcome the collaboration of all the patients who gave their consent for this study and welcome the team of department of clinical hematology of Yopougon teaching hospital for their contribution during the management of these patients.

\section{References}

1. Mahindra A, Kenneth H, Anderson KC (2010) Multiple myeloma: biology of the disease. Blood Rev 24(1): 511.

2. Harousseau JL, Dreyling M (2010) ESMO Guidelines Working Group, Multiple myeloma: ESMO Clinical Practice Guidelines for diagnosis, treatment and follow-up. Ann Oncol 21(5): 155-157.

3. Tamimi W, Alaskar A, Alassiri M, Alsaeed W, Alarifi SA, et al. (2010) Monoclonal gammopathy in a tertiary referral hospital. Clin Biochem 43(9): 709713.

4. Tolo DA, Sawadogo D, Nanho DC, Kouakou B, Méité N, et al. (2013) Characteristics and Results of the 
Treatment of Multiple Myeloma in the Subject under the Age of 65 at the University Hospital of Yopougon in Abidjan, Côte d'Ivoire. Adv Hematol 2013: 583051.

5. Malard F, Harousseau JL, Mohty M (2016) Prise en charge du myélome multiple en première rechute après autogreffe de cellules souches périphériques. Hematol 22(6): 395-405.

6. Ndiaye FS, Pouye A, Fall S, Diallo S, Ndongo S, et al. (2011) Présentation clinique du myélome multiple à Dakar (Sénégal): à propos de 71 observations. J Afr Cancer 3(1): 8-11.

7. Kyle RA (1975) Multiple myeloma: Review of 869 cases. Mayo Clin Proc 50(1): 29-40.

8. Bataille R, Donadio D, Morlock G (1979) Myélomes multiples des os: Etude rétrospective des facteurs pronostiques à partir d'une série de 243 malades. Rev Rhum 46(2): 77-83.

9. Ludwig H, Fritz E, Friedl HP (1982) Epidemiologic and age-dependent date on multiple myeloma in austria. J Nath Cancer Inst 68(5): 729-733.

10. Ngouadjeu Dongho TE, Doualla MS, Tolefac PN, EnowOrock G, Oben DT, et al. (2018) Multiple Myeloma in Cameroon: Clinico-Biological Characteristics of Patients; an Experience from Douala General Hospital. Haematol Int J 2(1): 000113.

11. Nwabuko OC, Igbigbi EE, Chukwuonye II, Nnoli MA (2017) Multiple myeloma in Niger Delta, Nigeria: complications and the outcome of palliative interventions. Cancer Manag Res 9: 189-196.

12. Olaniyi JA, Fowodu FO (2015) Multiple myeloma: The burden and clinico-laboratory characteristics in a Nigerian foremost tertiary hospital. J Appl Hematol 6(2): 58-63.

13. Madu AJ, Ocheni S, Nwagha TA, Ibegbulam OG, Anike US (2014) Multiple myeloma in Nigeria: an insight to the clinical, laboratory features, and outcomes. Niger J Clin Pract 17(2): 212-217.
14. Ndomocrah A, Ouavene JO, Mobima T, Yakelendji YB, Gosta AJ, et al. (2013) Aspects epidemiologiquescliniques-radiologiques, therapeutiques et evolutifs $\mathrm{du}$ myelome multiple a l'hopital de l'amitie de BANGUI. J Afr Imag Médicale 5(3): 159-163.

15. Younes M, Hachfi H, Hammouda F, Younes K, Ben Hammouda S, et al. (2014) Les facteurs pronostiques de survie au cours du myélome multiple. Tunis Med 92(6): 399-405.

16. Terriou L, Leleu X, Yakoub-Agha I.( 2006). Traitement du myélome multiple. Bulletin du cancer; 93 (1): 1016.

17. Député de Curado, Oliveira MM, DR Silva, Souza DL (2018) Epidémiologie du myélome multiple dans 17 pays d'Amérique latine: mise à jour. Médicament contre le cancer 7(5): 2101-2108.

18. Tang $\mathrm{CH}$, Liu HY, Hou HA, Qiu H, Huang KC, et al. (2018) L'épidémiologie du myélome multiple à Taiwan, une étude basée sur la population. Epidém cancer 55: 136-41.

19. Carli PM, Bailly F, Tavernier C, Milan C, Heudes D, et al. (1989) Myélome multiple: caractéristiques épidémiologiques dans une population bien définie en Bourgogne, en France. Journ int Epidém 18: 330333.

20. Nnonyelum ON, Anazoeze MJ, Eunice NO, Emmanuel 00, Stella AT, et al. (2015) Multiple myeloma in Nigeria: a multi-centre epidemiological and biomedical study. Pan Afr Med J 22: 292.

21. Ngouadjeu Dongho TE, Wouakam Matchim D, Tomowiak C, Doualla MS, Fewou A, et al. (2018) Survie globale des patients âgés de moins de 65 ans, porteurs de myélome multiple sous chimiothérapie à l'hôpital général de Douala. Rev Méd Pharm 8(1): 751-761.

22. Legriel S, Azoulay E (2008) Complications neurologiques du patient d'oncohématologie. Réanimation 17(7): 681-694. 